\title{
Existence of a Surface Configuration on the Aerial Spore and Aerial Mycelium of Micropolyspora
}

\author{
By K. TAKEO \\ Department of Bacteriology, Chest Disease Research Institute, \\ Kyoto University, Kyoto, Japan
}

(Received I4 May 1975; revised 7 October 1975)

SUMMARY

We report the existence of a surface configuration in a true spore-forming genus having cell wall constituents of type IV. Micropolyspora angiospora, $M$. caesia and $M$. faeni freeze-fractured along the wall surface and only had a surface configuration on their aerial mycelium and aerial spores, with none on the substrate mycelium and substrate spore. The surface configuration of Micropolyspora was distinctly more complicated than that of Nocardia. The aerial spores of $M$. angiospora were characteristic in that they possessed ridges, two kinds of surface configurations (i.e. rodlets and fibres), and a complex pattern on the surface. Some rodlets of this organism were formed of a two-stranded helix, each strand having a diameter similar to that of a fibre.

\section{INTRODUCTION}

Takeo \& Uesaka (1975) reported that Nocardia almost always freeze-fractured along the wall surface, and that both the aerial and substrate mycelia of Nocardia showed a simple surface configuration made up of 'rodlets'. They suggested that this configuration might be a form ancestral to those found in true spore-forming Actinomycetales. Therefore some true spore-forming members of the family Nocardiaceae may have a surface configuration made up of rodlets, distinctly more complex than that of Nocardia. The surface configuration made up of rodlets has a wide distribution, being found on the endospores of eubacteria (Holt \& Leadbetter, I969), arthro- or endospores of Actinomycetales, and fungal spores (Hess, Sassen \& Remsen, 1968; Hess \& Stocks, 1969). In Actinomycetales, however, this surface configuration has been reported only in members of Streptomyces (Vernon, I955; Hopwood \& Glauert, I96I; Wildermuth, Wehrli \& Horne, I97I; Williams et al., 1972), Streptoverticillium (Cross, Attwell \& Locci, 1973), Thermoactinomyces (McVittie, Wildermuth \& Hopwood, 1972) and Actinomadura (Williams, Sharples \& Bradshaw, 1974). The present taxonomy for Actinomycetales is based both on the chemical constituents of the cell wall, and on morphology (Lechevalier, Lechevalier \& Gerber, 197I). However, the chemical constituents of these genera differ from those of Nocardia, which has cell wall constituents of type IV (Becker, Lechevalier \& Lechevalier, 1965). Thus, they cannot be regarded as closely related to Nocardia. According to Lechevalier et al. (I97I), the family Nocardiaceae contains Micropolyspora, Thermomonospora, and Pseudonocardia as true spore-forming genera, whereas Cross \& Goodfellow (1973) regarded Micropolyspora as being the only true spore-forming genus in the family Nocardiaceae.

This paper describes the surface structure of Micropolyspora angiospora, M. caesia and $M$. faeni, and reports the existence of a surface configuration for the true spore-forming Actinomycetales having cell wall constituents of type IV. 


\section{METHODS}

Organisms and growth conditions. Micropolyspora angiospora IFOI3I55 (LIA3479/30), $M$. caesia KCC, A-98 and $M$. faeni KCC, A-99, kindly donated by Dr A. Seino of the Kaken Chemical Co. Ltd, were used. The organisms were grown on either Bennets agar (Waksman, 196I) or NZ-amine-glycerol agar (Lechevalier, Solotorovsky \& McDurmont, I96I) at $37^{\circ} \mathrm{C}$ for 3 to I4 days, except that cultures up to 2 months old were used if they were to be negatively stained. Micropolyspora angiospora produced plenty of aerial mycelium and spores, and was studied in detail. Micropolyspora caesia and M. faeni showed poor growth of the aerial mycelium and spores. About ten media usually used for spore production in Actinomycetales were tested, but none were noticeably better than Bennets medium and NZ-amine-glycerol agar.

Electron microscopy. Growths rich in aerial mycelium and spores were transferred directly, or after fixation and cryoprotection, to the specimen holder of the freeze-etching apparatus. If transferred directly, $30 \%$ glycerol was added as a glue immediately before cooling. The fixation and freeze-etching methods were those described by Takeo et al. (1973), with minor modifications. Samples for shadow casting were made simply by pressing collodion-coated grids gently on to the growths before shadowing. Negative staining was done essentially as by Wildermuth (1972), except that $2 \%$ phosphotungstate was used. Unless negative staining had been employed, the electron micrographs were printed in reverse to facilitate interpretation.

RESULTS

Aerial mycelium and spores

\section{Micropolyspora angiospora}

Aerial mycelium and spores of $M$. angiospora almost always freeze-fractured along the outer surface. Micropolyspora angiospora showed polymorphic forms of aerial spores, varying from rod-shaped to nearly spherical (Fig. I), as with $M$. rectivirgula (Dorokhova et al., 1970). The structural features of the spore surface seemed to vary with the shape of the spores. The most conspicuous structure of the aerial spore was a pattern of ridges about $100 \mathrm{~nm}$ high and wide, and sometimes extending more than half way around the spore (Fig. I). To check that the ridges were not an artefact, three different methods of observation were used: (i) freeze-etching without pretreatment; (ii) freeze-etching after fixation and cryoprotection; and (iii) shadowing alone. These all confirmed the existence of ridges on mature spores, although some spores did not show them - a spore that has just formed may have a smooth surface (Fig. I $a$ ).

Cross-fracturing of the spore was rare but when it occurred, it revealed a thick wall (Fig. I $d$ ). One part of the wall was densely covered in particles, a feature commonly observed when the freeze-etching technique is used. The other part of the wall, however, was smooth, indicating a low content of macromolecules there. A thick spore wall in this genus has already been reported in $M$. rectivirgula (Dorokhova et al., 1970).

As shown in Fig. I, the fine structure of the spore surface of $M$. angiospora appeared complex. Two kinds of linear configurations were observed together on the same cells. One had a diameter of 6 to $8 \mathrm{~nm}$ and the other a diameter of 3 to $4 \mathrm{~nm}$. The thicker kind will be referred to as rodlets and the thinner as fibres, since the latter had diameters similar to those reported for the fibres on the spore surfaces of Thermoactinomyces vulgaris (McVittie et al., 1972) and of Bacillus fastidiosus (Holt \& Leadbetter, 1969). The configuration found on the flat surface of the spore was almost always fibres. About ten fibres ran parallel, with a 

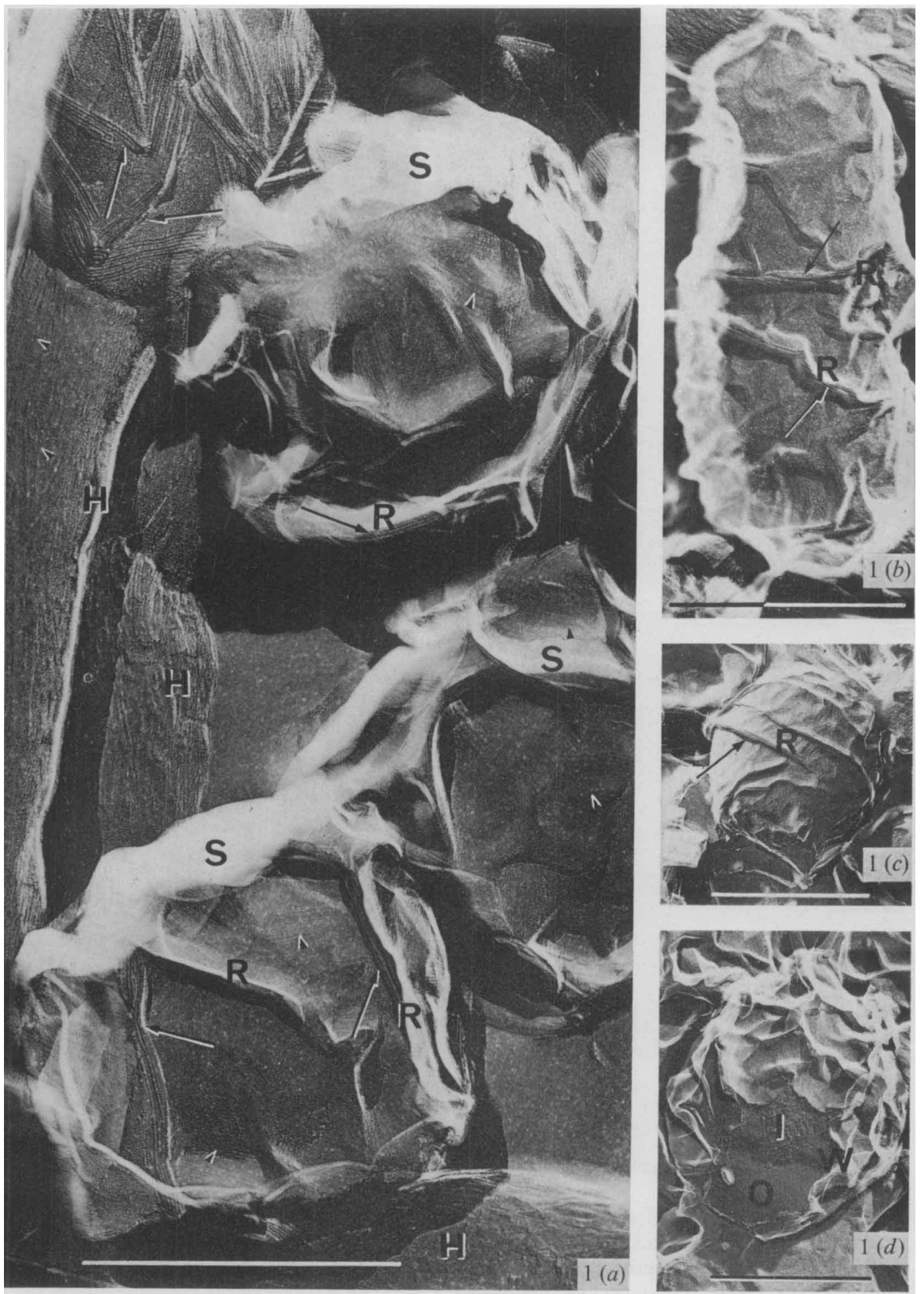

Fig. I. Freeze-fracture of $M$. angiospora showing surface view of aerial spores (S) and aerial hyphae (H). Aerial spores show ridges (R), parallel rodlets (arrows) on the ridges, and fibres (arrowheads). Aerial hyphae show only long fibres. (a). Part of aerial hypha seems to be in transition to the spore phase (upper left). (b). Long spore. (c). Spherical spore. $(d)$. Cross-fracture of aerial spores showing a thick wall (W). A part of the wall (I) is densely covered with particles, while another part $(\mathrm{O})$ is smooth. Bar markers represent $1 \mu \mathrm{m}$. 

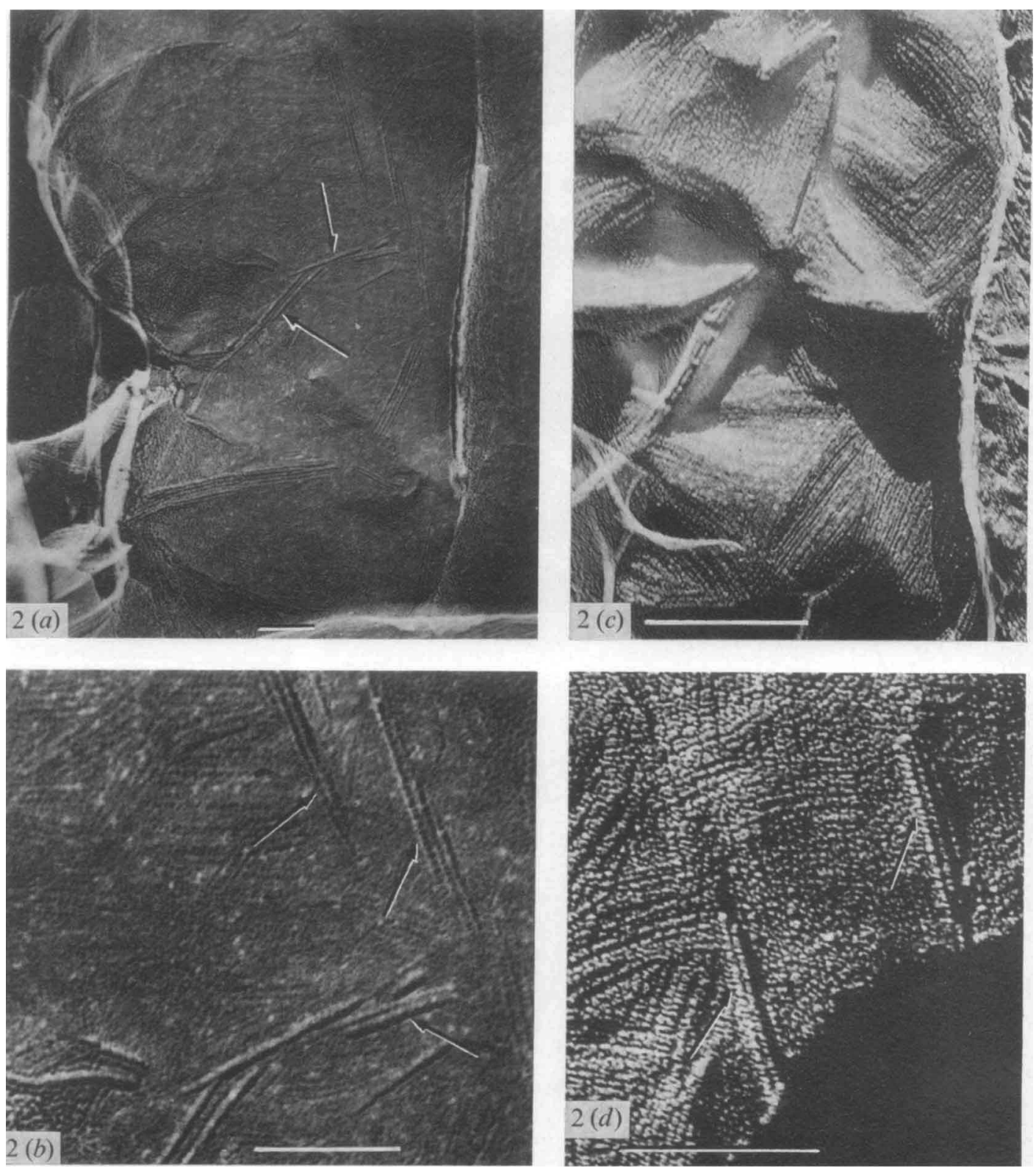

Fig. 2. Freeze-fracture of part of a swollen aerial hypha of $M$. angiospora, showing surface structure. $(a)$. Rodlets having a larger diameter than those found in aerial spores (arrows). $(b)$. Portion of $(a)$ at higher magnification. Rodlets show periodic striations lying obliquely to the long axis of the rodlets (arrows). (c). Fibres showing arrayed configuration. (d). Rodlets showing periodic substructure (arrows). Bar markers represent $0.2 \mu \mathrm{m}$.

centre-to-centre spacing of about $5 \mathrm{~nm}$, but they never adhered to each other, thus leaving a narrow gap between them.

The structure on the protruded surface, especially on the ridges, was predominantly composed of rodlets. On the ridges, about five rodlets ran parallel to the ridges and to each 
other, with a centre-to-centre spacing of about io $\mathrm{nm}$. The gaps between rodlets were two to three times wider than those between fibres (Figs. I and 2).

The surface configuration of the aerial mycelium was simpler than that of the aerial spore (Figs. I and 2). Protrusions, especially ridges, were rarely found. The fibres, which were predominantly found on most aerial mycelia, appeared to be more irregularly arrayed than those on the aerial spores. Often they ran at a small angle to the long axis of the aerial mycelium. As can be seen in Fig. 2, swollen aerial mycelia displayed more complicated configurations than those described above. Although they possessed no ridges, they had rodlets on the flat surface and showed diversity in the direction of the arrayed fibres. Some rodlets found on them had a larger diameter than those on the aerial spore, and resembled those of Nocardia (Takeo \& Uesaka, 1975) in both shape and size. On close scrutiny, rodlets displayed periodic striations lying obliquely to the long axes of the rodlets (Fig. $2 b$ and $d$ ). Furthermore, the diameters of the rodlets differed considerably, while the fibre thicknesses were relatively uniform. These facts suggest that the rodlets may be composed of smaller units.

To reveal the structure of the rodlets in more detail, negative staining was done. As shown in Fig. $3 a$, the spore showed fibres and rodlets as in freeze-etching. Some rodlets were found to be composed of a two-stranded helix (Fig. $3 b$ ). Each strand had a diameter similar to that of a fibre. The helix pitch was about $20 \mathrm{~nm}$, and the helical line made an angle of about $40^{\circ}$ to the long axis of the rodlets. The value for the pitch may be an overestimation and the angle an underestimation, because it is possible that only the loosened rodlets reveal the helical structure.

As for the surface pattern of the aerial mycelium, negative staining revealed a somewhat different feature from freeze-etching. As shown in Fig. 5, the aerial mycelium generally revealed relatively small numbers of fibres. Patterns resembling that in Fig. $2 c$ were not observed on the aerial mycelium, but such a pattern was observed outside the cell (Fig. 4). These facts suggest the existence of double-layered sheaths on the swollen aerial mycelium. In $M$. faeni, existence of the sheath was reported by Williams, Sharples \& Bradshaw (1973), and Dorokhova et al. (1970) found multilayered sheaths in $M$. rectivirgula.

\section{Micropolyspora caesia and M. faeni}

As shown in Figs. 6 to 8, M. caesia also revealed a linear configuration on the surface layer of aerial mycelium and spores. However, the pattern of the surface configuration of $M$. caesia was much simpler than that of $M$. angiospora: (i) the aerial mycelium and spores had a relatively smooth surface, never showed ridges, and both had a similar surface configuration; (ii) $M$. caesia had only short rodlets, about $100 \mathrm{~nm}$ long and 4 to $8 \mathrm{~nm}$ in thickness, as revealed by freeze-etching and shadow casting; (iii) the rodlets covered the spore surface but were not regularly arranged as in $M$. angiospora.

Cross-fracture of the spore revealed a wall about $100 \mathrm{~nm}$ thick, much thicker than that of the aerial mycelium (Fig. $6 a, b$ ). The spore wall was composed of two layers; the inner layer was densely covered with particles and resembled the wall of the aerial mycelium, while the outer layer was distinctly etched, indicating a low content of macromolecules and other substances which inhibit deep etching (Takeo \& Nishiura, 1974). This feature probably indicates that the spore sheath exists separately from the inner wall layer.

Another species of this genus, $M$. faeni, also revealed a surface configuration on the aerial mycelium and spores, which resembled that of $M$. caesia more closely than that of $M$. angiospora (Fig. Io $a, b$ ). The spore surface was covered with short rodlets about Ioo $\mathrm{nm}$ long. 

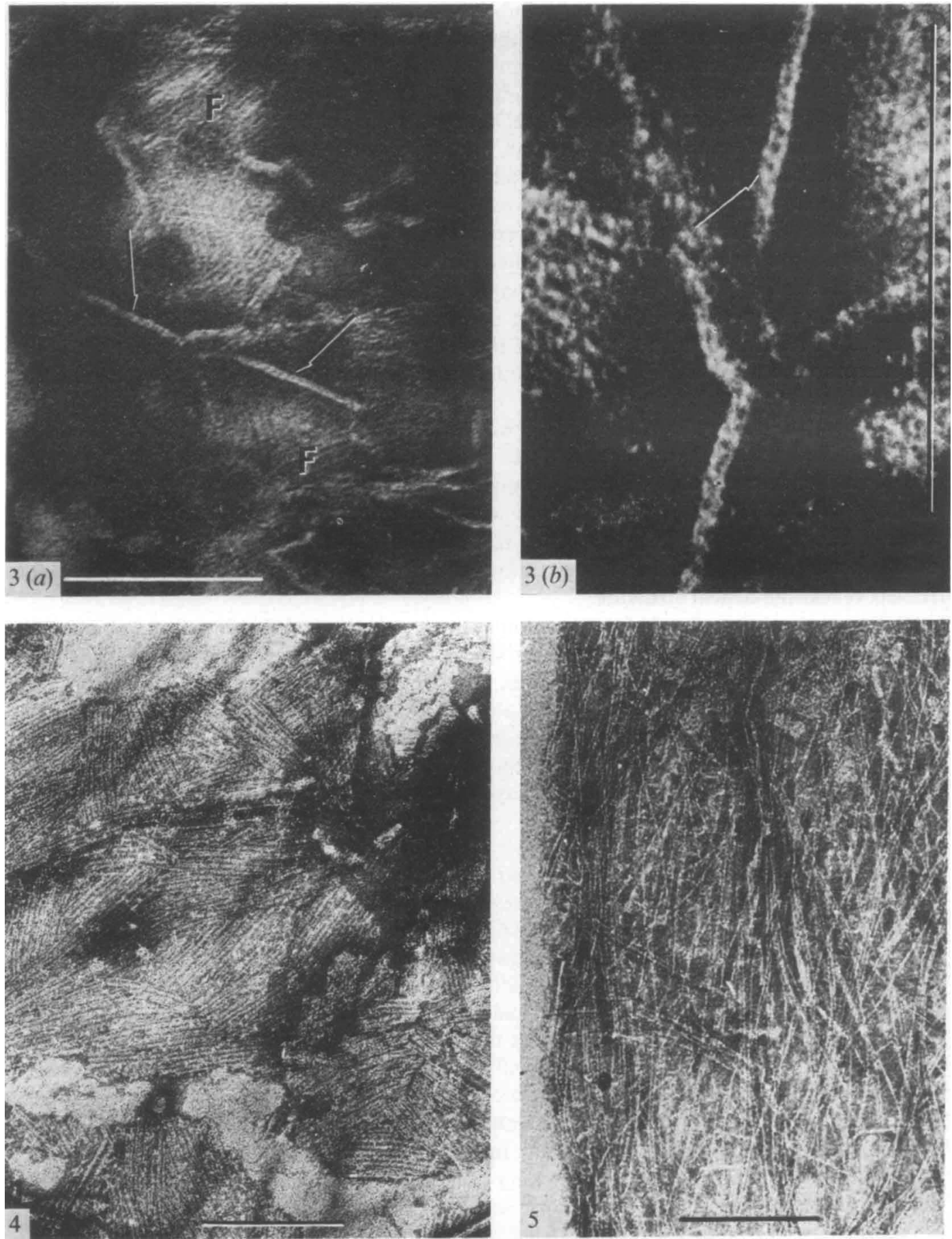

Fig. 3. (a) Negatively-stained spore surface of $M$. angiospora showing rodlets (arrows) and arrayed fibres (F). (b) Portion of (a) at higher magnification. Rodlets display a two-stranded helix (arrow). Bar markers represent $0.2 \mu \mathrm{m}$.

Fig. 4. Negative staining of the surface of $M$. angiospora outside the cell. The pattern resembles that of a swollen aerial hypha as observed by freeze-etching (see Fig. 2c). Bar marker represents $0 \cdot 2 \mu \mathrm{m}$.

Fig. 5. Negatively-stained aerial hypha of $M$. angiospora, showing relatively small numbers of long fibres. Bar marker represents $0.2 \mu \mathrm{m}$. 

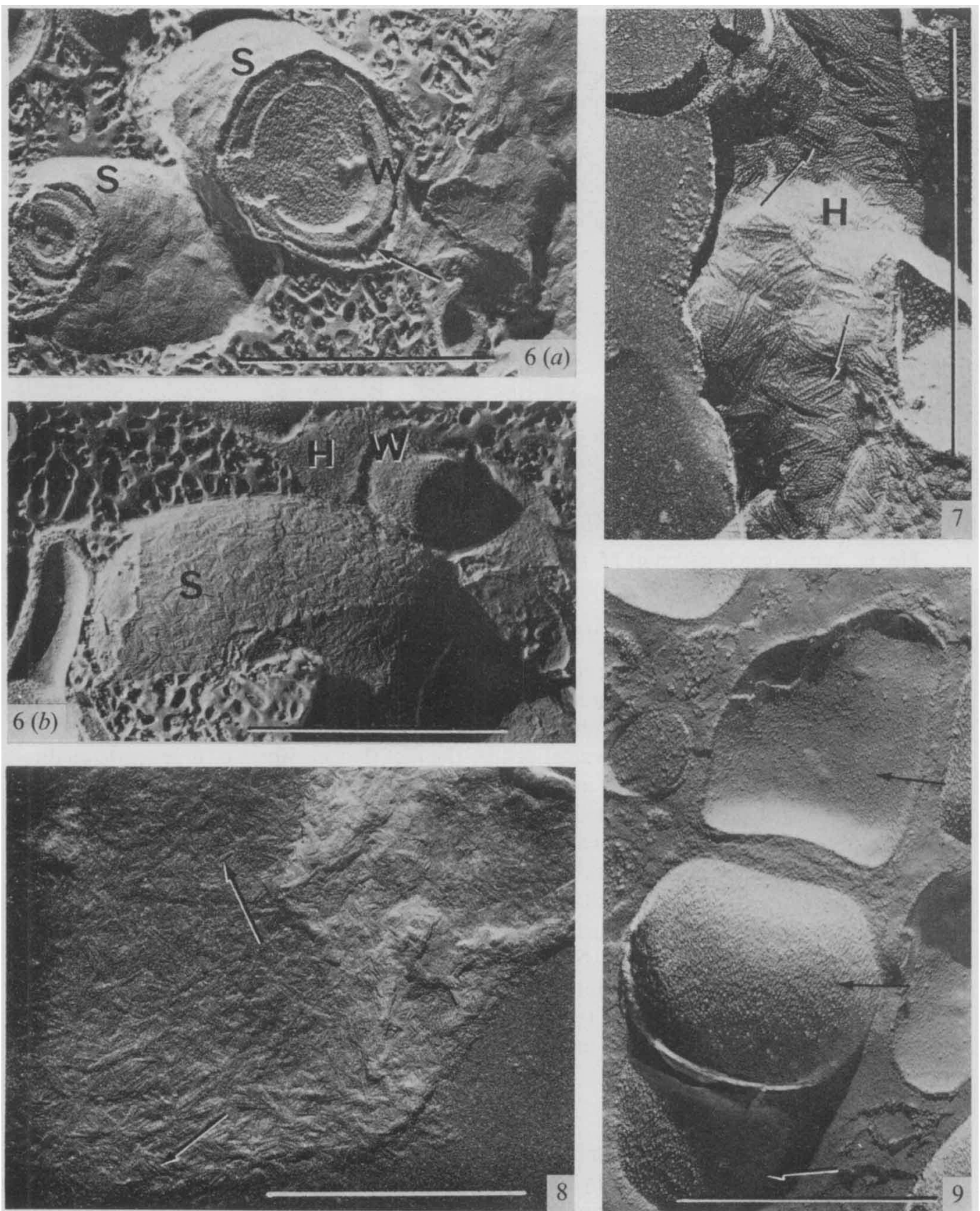

Fig. 6. Surface and cross-fractured view of freeze-etched aerial spores $(\mathrm{S})$ and aerial hypha $(\mathrm{H})$ of $M$. caesia. (a). Cross-fracture of an aerial spore, showing a thick and doubly-layered wall (W). The outer layer was deeply etched (arrow). (b). Cross-fracture of an aerial hypha, showing a thin wall (W). Bar markers represent I $\mu \mathrm{m}$.

Fig. 7. Freeze-fracture of aerial hypha $(\mathrm{H})$ of $M$. caesia, showing a surface configuration made by rodlets (arrows). Bar marker represents I $\mu \mathrm{m}$.

Fig. 8. Part of an aerial spore of $M$. caesia, showing surface rodlets (arrows), observed by shadow casting. Bar marker represents $\mathrm{I} \mu \mathrm{m}$.

Fig. 9. Freeze-etched cells of $M$. caesia observed among substrate hyphae. Spherical cells (arrows) may be substrate spores judging from their shape and size. Bar marker represents $\mathrm{I} \mu \mathrm{m}$. 

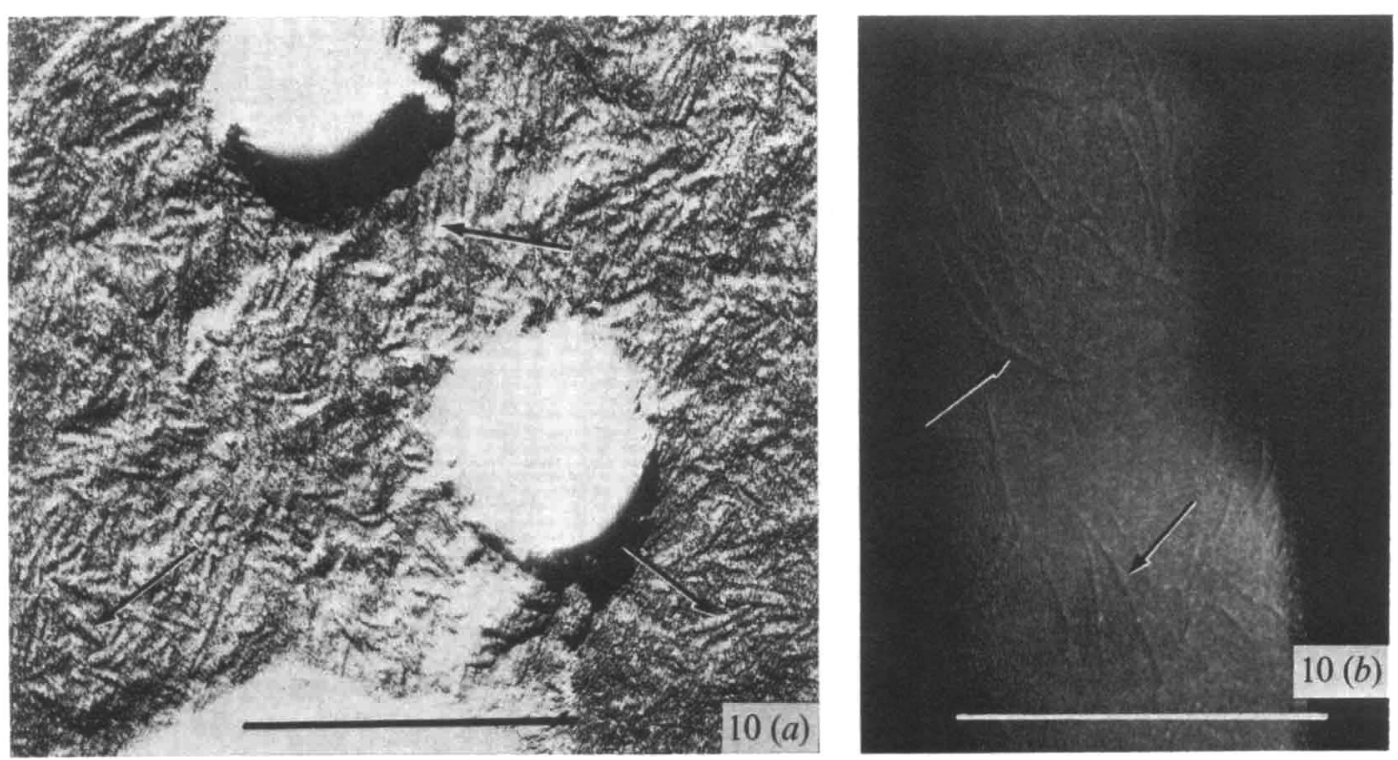

Fig. 10. Surface configuration of $M$. faeni observed by shadow casting. (a). Part of aerial spore showing rodlets (arrows). (b). Aerial hypha showing rodlets (arrows). Bar markers represent $0.5 \mu \mathrm{m}$.

\section{Substrate mycelium and spores}

The surface characteristics of the substrate mycelium differed distinctly from those of the aerial mycelium and spores. The three species of Micropolyspora never fractured along the wall surface of the substrate mycelium or showed a linear configuration.

The genus Micropolyspora is characterized by the fact that members of it generate chains of arthrospores both on the aerial and substrate mycelium (Lechevalier et al., 196r). The aerial spores, when observed in the electron microscope, existed in clusters, intermingled with the aerial mycelium which was discernible as such by characteristic surface configurations. Sometimes, spherical cells having a larger diameter than the usual substrate mycelium were observed among the substrate mycelium (Fig. 9). They never fractured along the wall surface or showed surface configurations. Judging from their shape and size, they may be the substrate spores. No fractures along the wall surface or surface rodlet configurations were observed, except where aerial mycelium and spores were observed in clusters. These facts seem to show that the spores on the substrate mycelium have similar surface characteristics to substrate mycelium itself.

\section{DISCUSSION}

Micropolyspora, a true spore-forming genus having cell wall type IV and belonging to the family Nocardiaceae, has more complicated surface characteristics than Nocardia (Takeo \& Uesaka, 1975). The two can be compared as follows: (i) In Micropolyspora, a clear differentiation is observed between the aerial mycelium and its spore as one group, and the substrate mycelium and its spore as another; only the former freeze-fractures along the wall surface and reveals the surface configuration. In Nocardia, on the other hand, both aerial and substrate mycelium freeze-fracture along the wall surface and reveal a surface configuration. (ii) The spore surface of Micropolyspora is covered with a linear configuration and in a sense, reaches a completeness like that of Streptomyces (Williams et al., 1972), 
while in Nocardia the pattern is very simple. Thus, the results obtained support, or at least do not contradict, the suggestion that the Nocardia line is an ancestral form of surface configuration of the true spore-forming genera.

Only a small proportion of the spores in $M$. angiospora cross-fracture, and there are distinct differences between the surface pattern of the spores and the aerial mycelium. These facts suggest that the spore sheath covers the whole spore and that it is synthesized upon spore formation, rather than being a mere remnant of the sheath of the aerial mycelium. Streptomyces viridochromogenes is another example which shows distinct differences between the surface pattern of the spores and the aerial mycelium. Wildermuth (1972) reported that the rod-like unit of the spine found in this organism is composed of a bundle of fine fibrils.

As to the correlation between the ridges and parallel arrays of rodlets on the ridges, I suggest the following interpretation as the simplest explanation. The ridges of $M$. angiospora are actually only wrinkles in the spore sheath, and not the counterpart of the ridges of fungal spores. For example, the ridges of the sporangiospore of Rhizopus are filled with wall materials (Hawker \& Abbott, 1963). A spore of $M$. angiospora may have a smooth surface when just formed (see Fig. I $a$ ). Later, it shrinks a little, e.g. by loss of water in the wall. The part of the spore having many rodlets resists shrinkage because of the physical strength of the rodlets. According to this hypothesis, the ridges thus form naturally along the parallel array of the rodlets.

Possibly, the rodlets of $M$. angiospora are an example of a helical polymer of a globular unit. How the units of the rodlets gather together spirally, how the rodlets and fibres are formed in parallel arrangement, whether the helical strand of rodlets is the fibre, and why some structures become rodlets and some fibres, remain as interesting problems to be solved in future.

A preliminary study on Pseudonocardia and Saccharomonospora showed that they also possess a surface configuration. Surface configurations exist in some members of Streptomyces, Streptoverticillium and Chainia (unpublished), which have cell wall type I, and in Thermoactinomyces, Actinomadura and Actinobifida (unpublished), which have cell wall type III. The surface configuration seems to be fairly ubiquitous in nature in Actinomycetales which form spores borne on the aerial mycelium. It now seems important to study in detail the surface configurations of various actinomycetes in connexion with the analysis of the chemical composition of the isolated rodlets.

I thank Professor I. Uesaka for discussion and encouragement, Mrs E. Yamagishi, Mr T. Nonaka, Mrs Y. Takaoki and Mrs I. Shimizu for technical assistance, and Mr M. Corr of the Institute for Humanistic Science, Kyoto University, for help with the manuscript.

\section{REFERENCES}

Becker, B., Lechevalier, M. P. \& Lechevalier, H. A. (1965). Chemical composition of cell wall preparations from strains of various form-genera of aerobic actinomycetes. Applied Microbiology 13, $236-243$.

Cross, T. \& Goodfellow, M. (1973). Taxonomy and classification of the actinomycetes. In Actinomycetales: Characteristics and Practical Importance, pp. I I-I I 2. Edited by G. Sykes and F. A. Skinner. London and New York: Academic Press.

Cross, T., AtTwell, R. W. \& Locci, R. (1973). Fine structure of the spore sheath in Streptoverticillium species. Journal of General Microbiology 75, 42 I-424.

Dorokhova, L. A., Agre, N. S., KalakutskiI, L. V. \& Krasil'nikov, N. A. (1970). A study of the morphology of two cultures belonging to the genus Micropolyspora. Microbiology 39, 79-86.

Hawker, L. E. \& Aввотt, P. M. (1963). An electron microscope study of maturation and germination of sporangiospore of two species of Rhizopus. Journal of General Microbiology 32, 295-298. 
Hess, W. M. \& Stocks, D. L. (1969). Surface characteristics of Aspergillus conidia. Mycologia 6r, 560-57I.

Hess, W. M., Sassen, M. M. A. \& Remsen, C. C. (1968). Surface characteristics of Penicillum conidia. Mycologia 60, 290-303.

Holt, S. C. \& LeadbeTter, E. R. (1969). Comparative ultrastructure of selected aerobic spore-forming bacteria: a freeze-etching study. Bacteriological Reviews 33, 346-378.

Hopwood, D. A. \& Glauert, A. M. (I96I). Electron microscope observations on the surface structures of Streptomyces violaceoruber. Journal of General Microbiology 26, 325-330.

Lechevalier, H. A., Lechevalier, M. P. \& Gerber, N. N. (I971). Chemical composition as a criterion in the classification of actinomycetes. In Advances of Applied Microbiology, vol. 14, pp. 47-72. Edited by D. Perlman. New York and London: Academic Press.

Lechevalier, H. A., Solotorovsky, M. \& McDurmont, C. I. (1961). A new genus of the Actinomycetales: Micropolyspora gen. nov. Journal of General Microbiology 26, I I-1 8.

MCVittie, A., Wildermưth, H. \& Hopwood, D. A. (1972). Fine structure and surface topography of endospores of Thermoactinomyces vulgaris. Journal of General Microbiology 7r, 367-381.

TAKEO, K. \& NishiURA, M. (1974). Ultrastructure of polymorphic Mucor as observed by means of freezeetching. I. Vegetative growth of mycelium and arthrospore formation in submerged and aerated culture. Archives of Microbiology 98, $175-185$.

TAKEO, K. \& UESAKA, I. (1975). Existence of a simple configuration in the wall surface of Nocardia mycelium. Journal of General Microbiology 87, 373-376.

Takeo, K., Uesaka, I., Uehira, K. \& Nishiura, M. (1973). Fine structure of Cryptococcus neoformans grown in vitro as observed by freeze-etching. Journal of Bacteriology $113,1442-1448$.

VERNON, T. R. (1955). Spore formation in the genus Streptomyces. Nature, London 176, 935-936.

Wildermuth, H. (I 972). The surface structure of spores and aerial hyphae in Streptomyces viridochromogenes. Archiv für Mikrobiologie 81, 309-320.

Wildermuth, H., WeHri, E. \& HoRne, R. W. (197I). The surface structure of spores and aerial mycelium in Streptomyces coelicolor. Journal of Ultrastructure Research 35, I68-I80.

Williams, S. T., Bradshaw, R. M., Costerton, J. W. \& Forge, A. (1972). Fine structure of the spore sheath of some Streptomyces species. Journal of General Microbiology 72, 249-258.

Williams, S. T., Sharples, G. P. \& Bradshaw, R. M. (1973). The fine structure of the Actinomycetales. In Actinomycetales: Characteristics and Practical Importance, pp. I13-130. Edited by G. Sykes and F. A. Skinner. London and New York: Academic Press.

Williams, S. T., Sharples, G. P. \& Bradshaw, R. M. (1974). Spore formation in Actinomadura dassonvillei (Brocq-Rousseu) Lechevalier and Lechevalier. Journal of General Microbiology 84, 4I 5-4I 9.

Waksman, S. A. (I96I). In The Actinomycetes, vol. 2, p. 33 I. Baltimore: The Williams and Wilkins Co. 